\title{
Urologische zorg bij transgenders in Nederland
}

\author{
Garry Pigot ${ }^{1}$ Brechje Ronkes ${ }^{1}$ Mark Bram Bouman ${ }^{2}$
}

Published online: 5 November 2018

(c) The Author(s) 2018

\section{Samenvatting}

Genderdysforie kenmerkt zich door incongruentie tussen het geboorte- en het gewenste geslacht. Transgenders zijn patiënten met genderdysforie die genderbevestigende medische behandelingen willen ondergaan. De medische zorg van mensen met genderdysforie gebeurt multidisciplinair volgens de Standards of Care (SOC) van the World Professional Association for Transgender Health (WPATH). Op basis van shared decision making worden de medicamenteuze en operatieve behandelingen ingesteld. De afdeling Urologie is medeverantwoordelijk voor functionele en esthetische resultaten van de genitale geslachtsaanpassende operaties bij de transgenders.

Trefwoorden genderdysforie $\cdot$ transgenders $\cdot$ vaginaplastiek $\cdot$ falloplastiek $\cdot$ metaidoïoplastiek

\section{Urological care for transgender patients in the Netherlands}

\begin{abstract}
Gender dysphoria is characterized by incongruity between the birth and the desired gender. Transgenders are patients with gender dysphoria who want to undergo gender-confirming medical treatment. The medical care of people with gender dysphoria is multidisciplinary and according to the Standards of Care (SOC) of the World Professional Association for Transgender Health (WPATH). Based on shared decision making, the medical and operative treatments are set. The Urology department is jointly responsible for functional and aesthetic results of the genital gender confirming surgery in the transgender.
\end{abstract}

Keywords gender dysphoria $\cdot$ transgenders $\cdot$ vaginoplasty $\cdot$ phalloplasty $\cdot$ metaidoioplasty

\section{Introductie}

In de vijfde editie van het Handboek voor de classificatie van psychische stoornissen (DSM-5) is de classificatie 'Genderdysforie' opgenomen. Genderdysforie is het diepe gevoel van onbehagen dat iemand ervaart als geboortegeslacht en genderidentiteit niet overeenkomen. Om stigmatisatie te vermijden en klinische zorg mogelijk te maken, is er in de DSM-5 voor gekozen om de classificatie 'Genderidentiteitsstoornis' te vervangen voor 'Genderdysforie' [1].

drs. Garry Pigot

garry.pigot@vumc.nl

1 afdeling Urologie, AmsterdamUMC, locatie VUmc, Amsterdam, Nederland

2 afdeling Plastische, Reconstructieve en Hand chirurgie, Amsterdam UMC, locatie VUmc, Amsterdam, Nederland
Transgenders zijn mensen met genderdysforie die in het kader van hun transitietraject genderbevestigende medische behandeling ondergaan middels hormonen en/of operaties.

The World Professional Association for Transgender Health (WPATH) is een internationale multidisciplinaire organisatie van gezondheidszorgers die middels de Standards of Care (SOC) een handleiding hebben ontwikkeld om de zorg van transgenders, transseksuelen en genderneutrale mensen te waarborgen [2]. Deze multidisciplinaire zorg omhelst de psychologie/psychiatrie, endocrinologie, gynaecologie, plastisch chirurgische, urologie, kno en kaakchirurgie. Het transitietraject wordt verdeeld in drie fasen: de diagnostische fase, de hormonale behandeling en de operaties. Na het bevestigen van genderdysforie kan invulling worden gegeven aan de hormonale en chirurgische behandeling. Dit traject wordt ingezet op basis van shared decision making. De urologie is betrokken bij de fase van de operatieve behandeling, met name als het gaat om de 
vrouw-naar-man genitale geslachtsaanpassende operaties (GAO) en is medeverantwoordelijk voor de functionele en esthetische resultaten.

Het doel van de genitale GAO is het creëren van een esthetisch representatief genitaal met goede seksuologische en urologische functie. De chirurgische behandelingen zijn vaak de laatste stappen in de behandeling van de genderdysforie en kunnen bijdragen aan het psychologisch welbevinden en de kwaliteit van leven van de transgenders [3].

Een body mass index (BMI) tussen de 18 en 30 en minstens zes weken stoppen met roken zijn criteria waaraan onder andere moeten worden voldaan om in aanmerking te komen voor de genitale GAO.

\section{Man-naar-vrouw geslachtsaanpassende operatie}

De genitale geslachtsaanpassende operatie bij man-naarvrouw transgenders, ook wel transvrouwen genoemd, gebeurt middels een vaginaplastiek. De meest gebruikte techniek is de penisinversietechniek, waarbij de huid van de penis wordt gebruikt als vaginawand. Deze techniek wordt in Nederland door de plastisch chirurg verricht. Bij een tekort aan lengte van de penishuid (bijvoorbeeld bij on- derontwikkeld mannelijk genitaal door op jonge leeftijd te starten met pubertijdsremmers en hormonale therapie of bij status na circumcisie) of bij secundaire vaginaplastieken na een mislukte penisinversietechniek, wordt een darmvagina gebruikt [4]. De darm-vaginaplastieken zijn gecombineerde sessies waarbij de plastisch chirurg de uitwendige genitalia reconstrueert en de holte maakt voor de vagina, terwijl de gastro-enterologische chirurgie simultaan laparoscopisch een stuk darm (sigmoïd of ileum) vrijprepareert. De orale zijde wordt gefixeerd aan het sacrum en de aborale zijde wordt ter hoogte van de neo-introïtus ingehecht.

De labia majora worden gereconstrueerd uit het scrotum, de labia minora en de clitorishoed van het preputium. De clitoris wordt gemaakt van het dorsale deel van de glans, daar is dan ongeveer een derde van nodig, waarbij de intact gelaten neurovasculaire bundel zorgt voor de sensibiliteit en de vascularisatie. Intermitterende zelfdilatatie van de neovagina is nodig voor behoud van de diepte en breedte. Zie fig. 1.

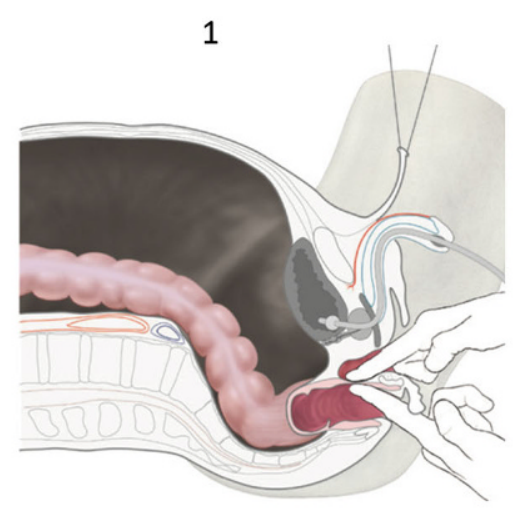

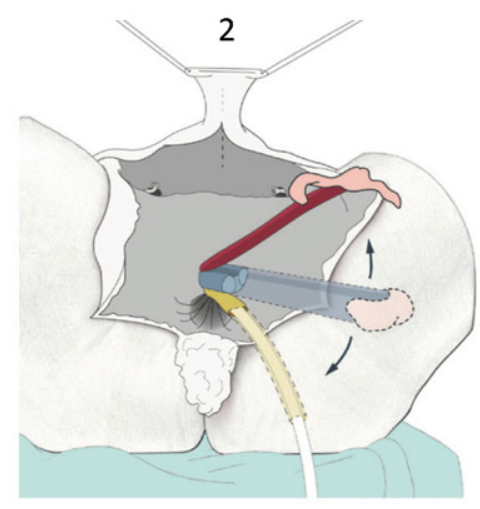

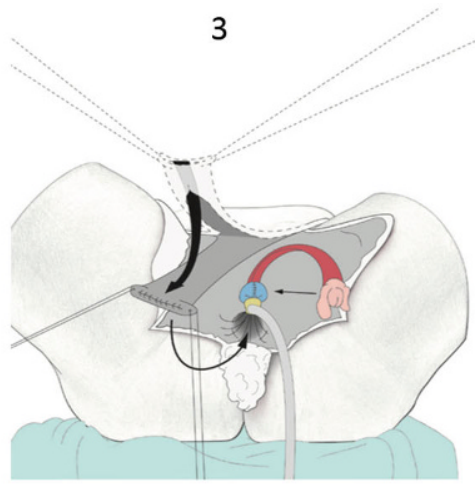

4

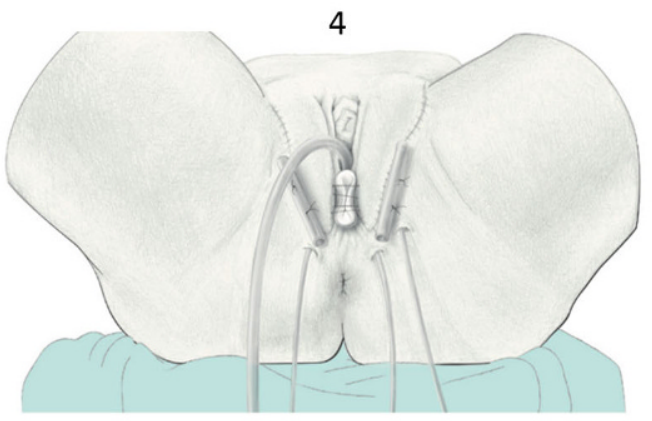

Figuur 1 De operatieve stappen bij de vaginaplastiek middels penisinversie. a Creëren van de vaginaholte; b situatie na deglovement van de penis, mobiliseren van de neurovasculaire bundel, creëren van de clitoris met clitorishoed, het verwijderen van het corpus spongiosum, de corpora cavernosa en de testikels; c inversie van de penishuid, fixeren van de clitoris, inhechten van de meatus urethra; $\mathbf{d}$ eindresultaat met de labia majora, labia minora, clitoris met clitorishoed, introïtus en de meatus van de urethra met transurethrale katheter. (Illustratie: Dana Hamers Scientific Art) 
a

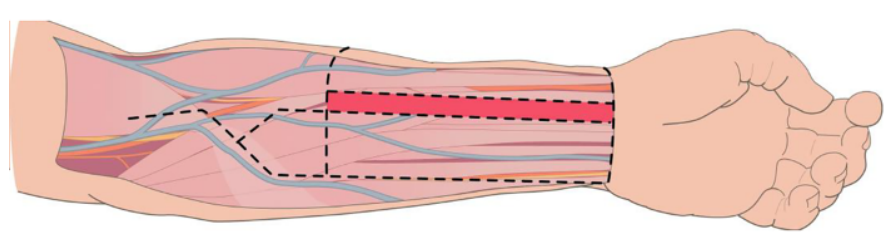

b

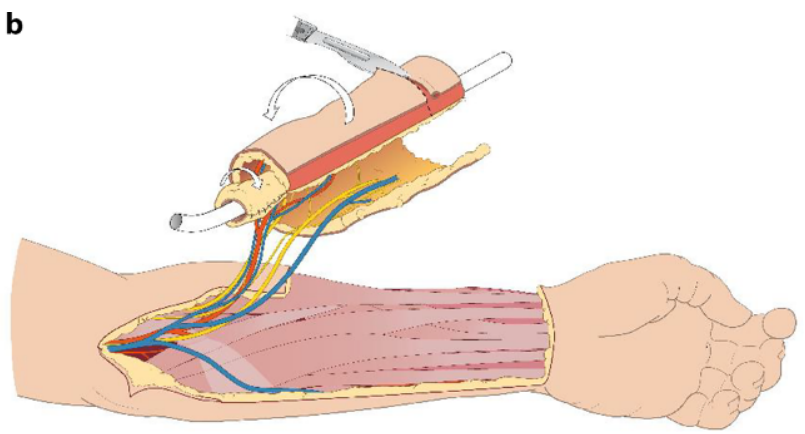

Figuur 2 a Aftekenen van de free radial forearm flap. b Situatie na vrijprepareren van de lap en voordat deze wordt ontkoppeld van de vaten en de zenuw. (Illustratie: Dana Hamers Scientific Art)

\section{Vrouw-naar-man geslachtsaanpassende operatie}

De genitale geslachtsaanpassende operatie bij vrouw-naarman transgenders, ook wel transmannen genoemd, gebeurt door de falloplastiek met scrotumplastiek of de metaidoïoplastiek. Bij beide technieken kan worden gekozen voor het wel of niet verlengen van de urethra (de mogelijkheid om staand te plassen of zittend blijven plassen).

Bij de falloplastiek wordt de fallus geconstrueerd van een gesteelde of een vrije lap. Deze lap bestaat uit huid en vet en is gevasculariseerd en geïnnerveerd. De meest gebruikte lappen zijn de free radial forearm flap (FRFF), een vrije lap, en de antero lateral thigh (ATL) flap, een gesteelde lap. Zie fig. 2.
Andere lappen waarvan gebruikgemaakt wordt zijn de superficial circumflex iliac artery perforator flap (SCIP) als gesteelde lap vanuit de flank ter hoogte van de bekkenkam, de myocutane latissimus dorsilappen en buikhuidlappen. Het neoscrotum wordt gereconstrueerd van de labia majora, labia minora en prepubische huid. Twee gesteelde prepubische vetlappen worden in het neoscrotum getranspositioneerd en dienen als vulling.

Bij een verlenging van de urethra wordt het eerste deel van de neo-urethra, het pars fixa, gereconstrueerd van de binnenkant van de labia minora. Het tweede deel van de neo-urethra, het pars pendulans, is een huidbuis dat een deel van een vrije falluslap vormt of als aparte lap wordt vrij gelegd. Zie fig. 3, 4 en 5 .

In ons centrum zijn de genitale GAO middels falloplastiek + scrotumplastiek gecombineerde sessies, waarbij de
Figuur 3 a Aftekenen van de antero lateral thigh flap. b Na vrijprepareren van de lap. De lap wordt gesteeld verplaatst. (Illustratie: Dana Hamers Scientific Art) a

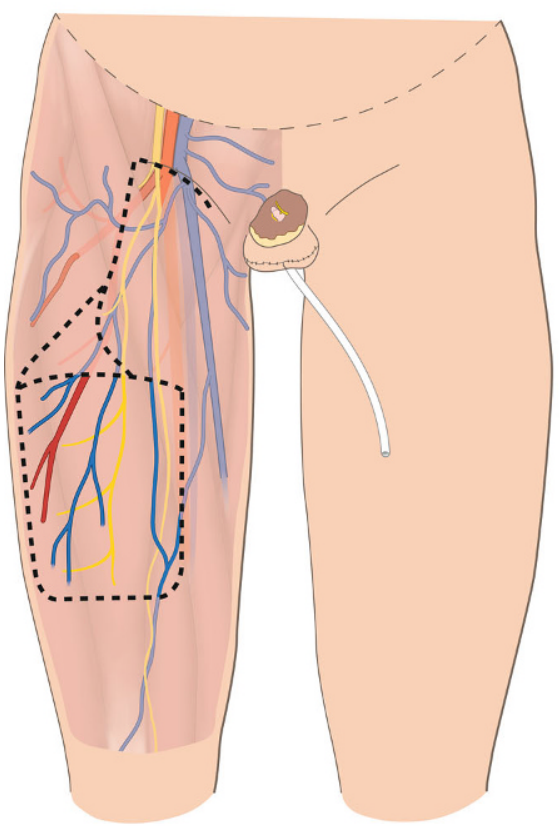

b

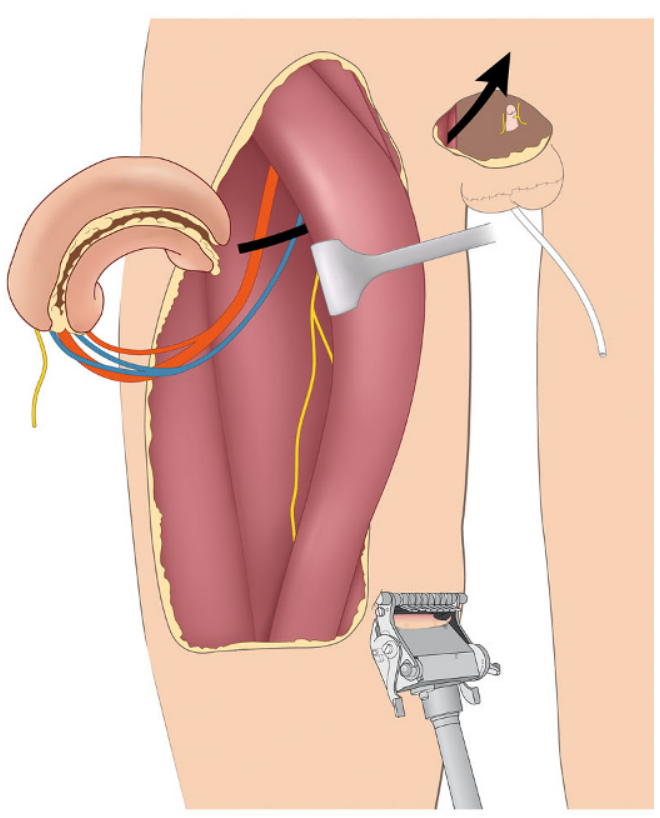


Figuur 4 Scrotumplastiek met plasbuisverlenging. a Aftekenen. b Insnijden. c Mobiliseren. d Reconstructie. (Illustratie: Dana Hamers Scientific Art) a

b

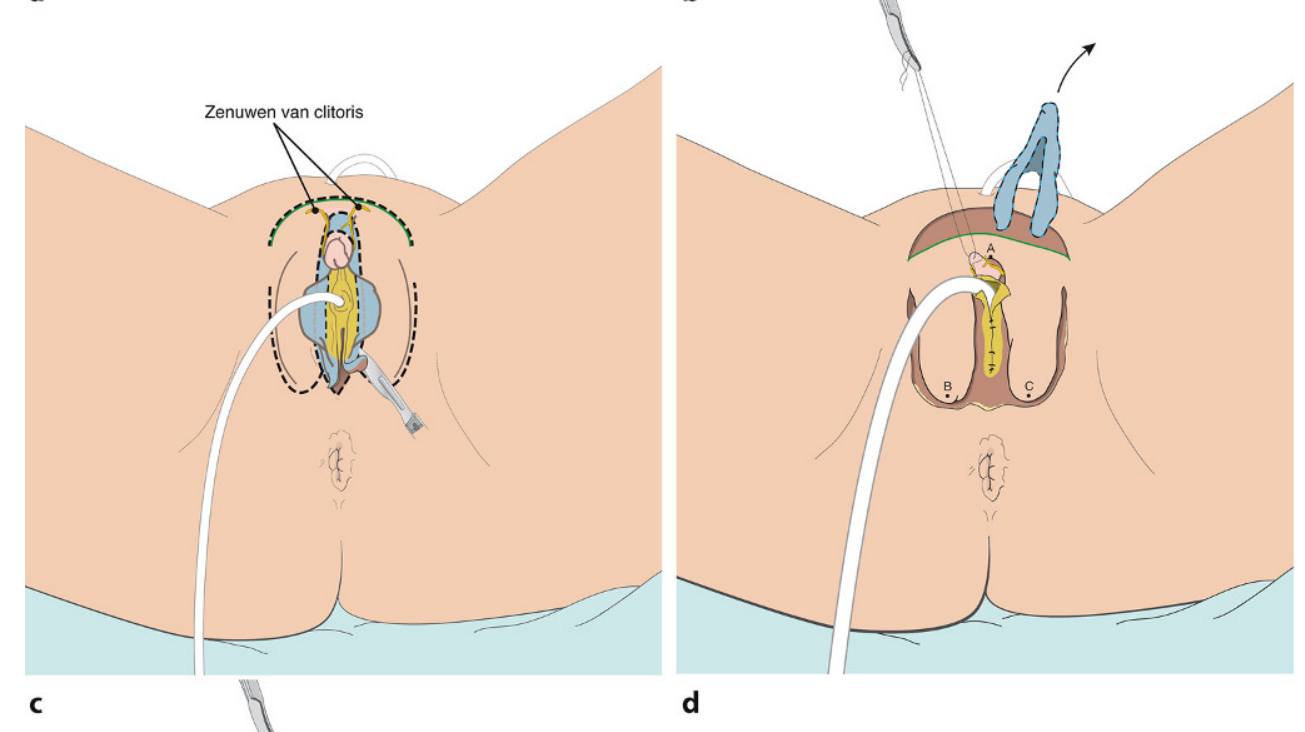

C

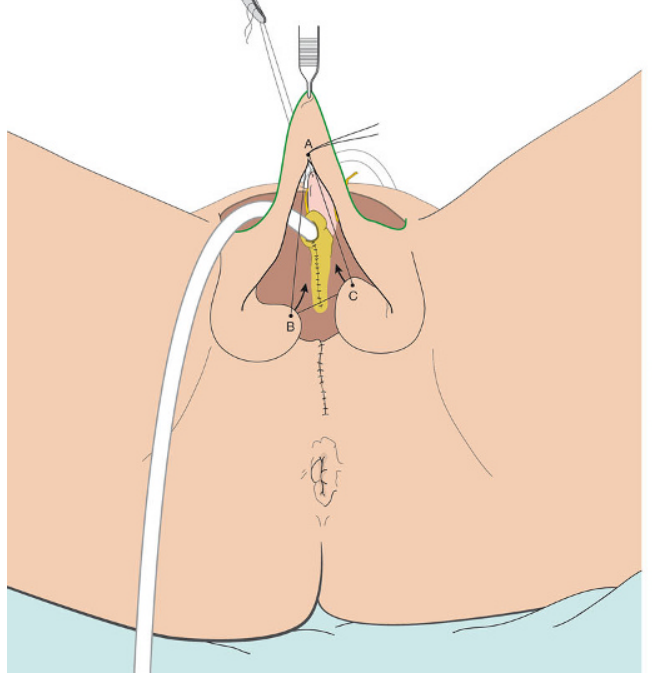

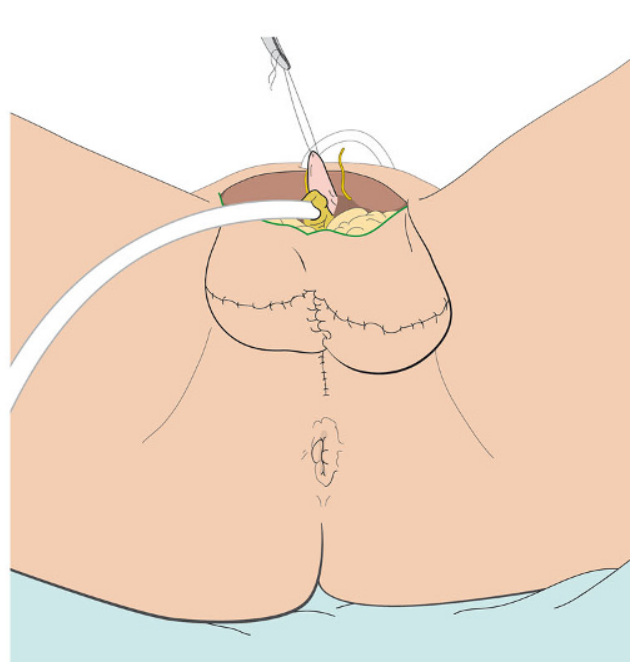

plastisch chirurg de lap vrijprepareert, terwijl de uroloog simultaan de scrotumplastiek al dan niet met urethraverlenging verricht.
Bij de metaidoïoplastiek wordt de fallus gereconstrueerd van de hypertrofische clitoris, waarbij dorsaal aan de basis de ligamenten fundiforme en suspensorie worden doorge- a

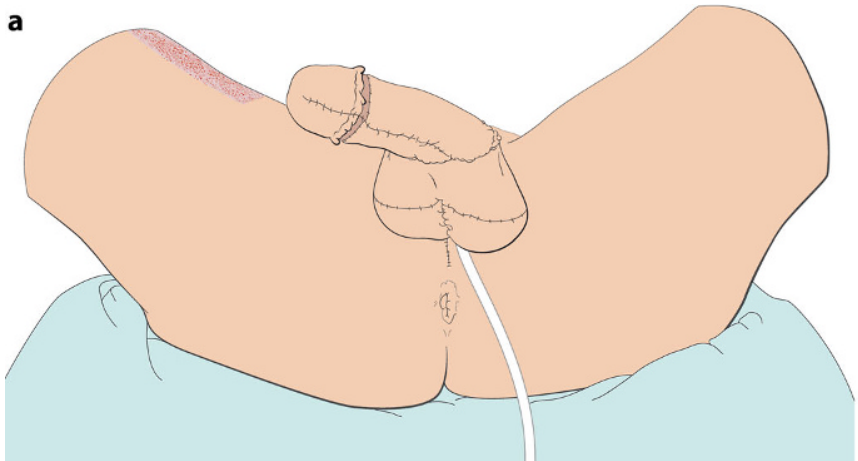

b

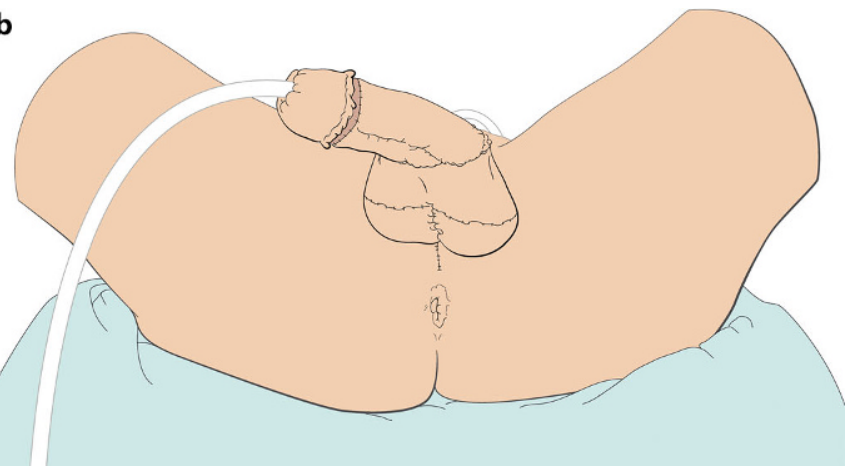

Figuur 5 Fallo- en scrotumplastiek. a Zonder urethraverlenging. b Met urethraverlenging. (Illustratie: Dana Hamers Scientific Art) 
Hier staat een advertentie.

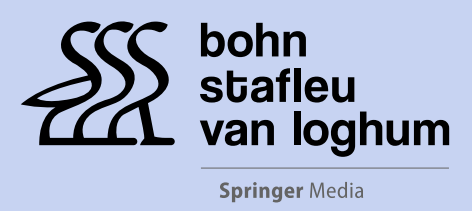

Houten 2018 
Hier staat een advertentie.

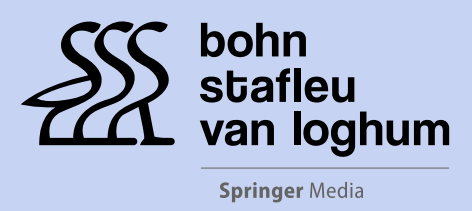

Houten 2018 
Hier staat een advertentie.

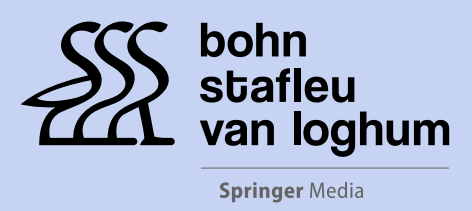

Houten 2018 
Hier staat een advertentie.

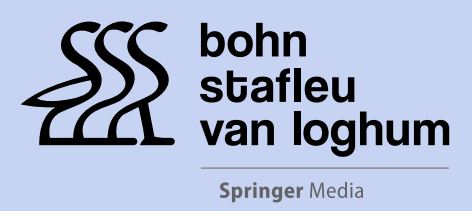

Houten 2018 
Figuur 6 Metaidoïoplastiek met urethraverlenging. a Aftekenen. b Insnijden en mobiliseren. c Eindresultaat. (Illustratie: Dana Hamers Scientific Art)
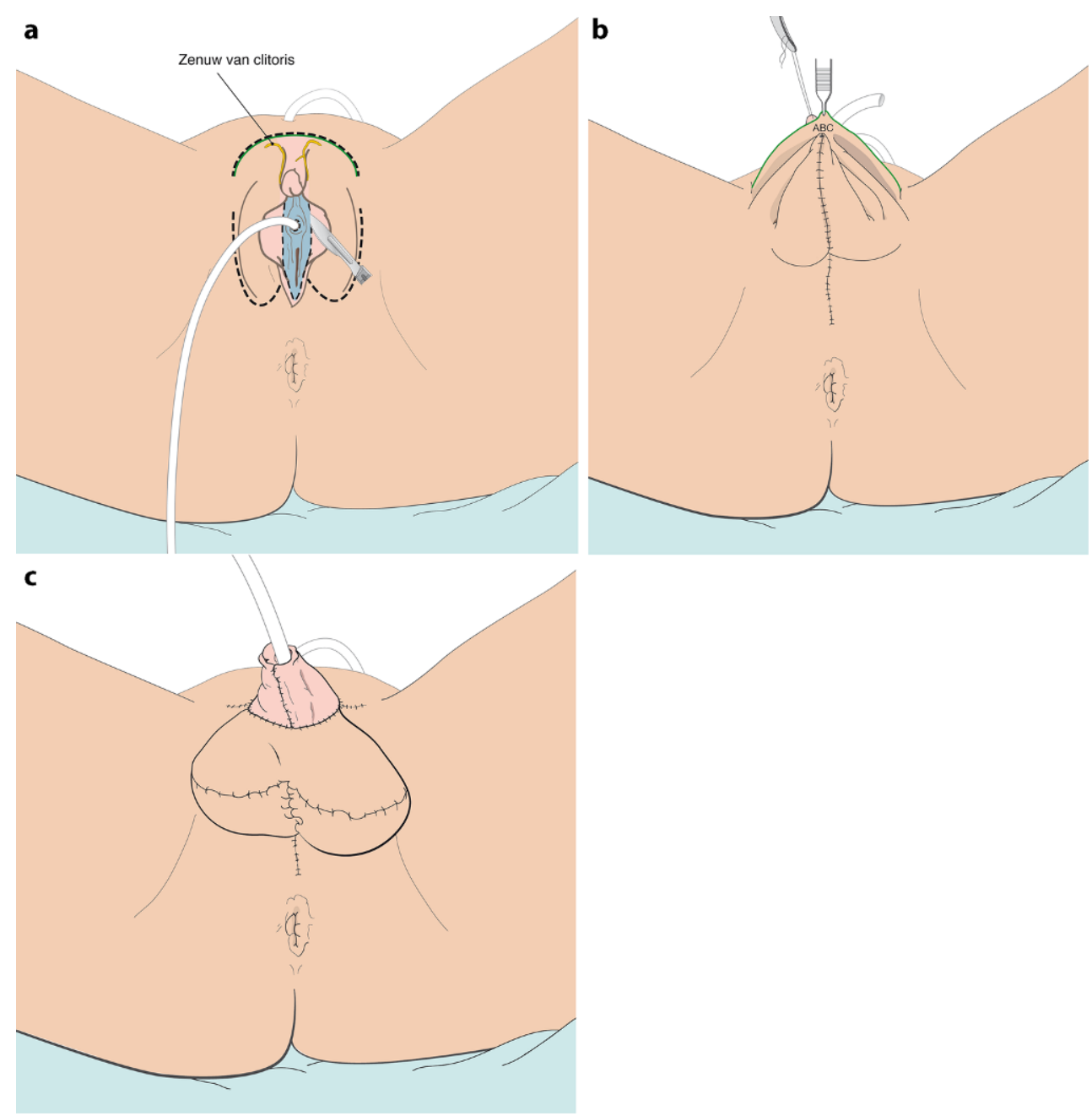

nomen en ventraal de clitoris wordt gestrekt. Het scrotum wordt gereconstrueerd van de labia majora, labia minora en prepubische huid. Bij de verlenging van de plasbuis wordt de labia minora gebruikt, soms in combinatie met wangslijmvlies (fig. 6).

De metaidoïoplastiek zonder plasbuisverlenging wordt verricht door de plastisch chirurg of de uroloog. Bij een plasbuisverlenging wordt de operatie door de uroloog en de plastisch chirurg verricht.

Voorafgaand aan de vrouw-naar-man genitale GAO vindt een laparoscopische hysterosalpingectomie plaats door de gynaecoloog, vaak gecombineerd met een mastectomie, die wordt verricht door de plastisch chirurg. Een colpectomie gebeurt als plasbuisverlenging gewenst is.

$\mathrm{Na}$ een geslaagde genitale geslachtsaanpassende operatie komen de transmannen in aanmerking voor een testisprothese en een erectieprothese. Voorwaarde voor het plaatsen van laatstgenoemde prothese is een goede urologische functie en sensibiliteit van de fallus.
Een testisprothese wordt na minimaal zes maanden geïmplanteerd. Via een midscrotale incisie worden er twee aparte holten gemaakt, waar de prothesen in worden geplaatst.

De erectieprothese wordt minimaal één jaar na de falloplastiek geplaatst. Bij de erectieprothese kan worden gekozen uit de semirigide en de hydraulische prothese. Het aantal cilinders ( 1 of 2 ) is afhankelijk van de grootte van de fallus.

Implantatie van de testisprothese wordt door de plastisch chirurg of de uroloog gedaan. De erectieprothese worden door de uroloog geplaatst. Bij de wens voor een besneden aspect van de penis wordt een glansplastiek verricht, eventueel gevolgd door het tatoeëren van de glans.

\section{Urologisch zorg bij de transvrouwen}

Preoperatieve urologische screening bij de transvrouwen vindt plaats door middel van een mictielijst, de interna- 
tional prostate symptom score (IPSS) en zo nodig een uroflowmetrie. $\mathrm{Er}$ is binnen het ons centrum consensus dat een IPSS van 10 of hoger een reden is om de transvrouw te verwijzen naar de urologie. Het aantal verwijzingen is laag en meestal kan worden volstaan met bekkenfysiotherapie. Postoperatieve urologische complicaties zijn met name meatusstenose en urethrastricturen. Deze komen weinig voor, maar vereisen wel operatieve behandeling. Sporadisch zien wij functionele postoperatieve mictieklachten, maar ook hier kan worden volstaan met bekkenfysiotherapie.

\section{Urologische zorg bij de transmannen}

Preoperatief worden alle transmannen urologisch geanalyseerd middels een mictielijst, de IPSS en een uroflowmetrie. Deze analyse gebeurt voor de colpectomie en voor de genitale GAO. Peroperatief is de uroloog verantwoordelijk voor de reconstructie van het neoscrotum, de reconstructie van het pars fixa en aansluiten van het pars fixa aan het pars pendulans.

De meeste urologische complicaties na de genitale GAO bij de transmannen zijn urethrastricturen en urethrafistels. Deze worden voornamelijk gezien bij de genitale geslachtsaanpassende operaties met verlenging van de urethra. Secundaire correcties en complicaties na implantatie van de erectieprothese komen bij ongeveer $40 \%$ van de patiënten voor.

\section{Discussie}

De medische zorg van transgenderpatiënten gebeurt multidisciplinair, waarbij de psychologische, interne en snijdende specialismen nauw samenwerken. Het unieke in deze zorg is dat chirurgische besluiten genomen worden op basis van diagnose en behandelingen die ingesteld zijn door psychologen en internisten. Logistiek gezien is dit zorg waarbij de behandelingen van de verschillende specialismen goed op elkaar worden afgestemd om vertraging in dit lange, ingewikkelde en ingrijpende traject te minimaliseren.

Er wordt wereldwijd een stijging van het aantal patiënten met genderdysforie gezien. Deze is deels te wijten aan meer publieke bekendheid en acceptatie van en openheid over genderdysforie. Daarnaast zijn er medisch-inhoudelijke ontwikkelingen die de kwaliteit van de zorg hebben verbeterd.

Zoals hiervoor beschreven, wordt op basis van shared decision making een keuze gemaakt voor de geslachtsaanpassende operatie. Voor de transvrouwen wordt de vaginaplastiek voornamelijk gekozen op medische gronden. Bij de transmannen is primair de voorkeur van de patiënt leidend en zijn er uitgebreidere keuzemogelijkheden. Denk aan de wens om staand te plassen, de wens voor penetratieve seks, donorsite littekens, behoud van gevoel van het genitaal. Dit zijn allemaal punten die medebepalend zijn. Om een meer weloverwogen beslissing te kunnen nemen voor het type genitale GAO is voor de transmannen een keuzehulp ontwikkeld [5]. Uiteindelijk wordt op basis van de wens van de patiënt en de fysieke, psychische en urologische factoren tot een gezamenlijke beslissing gekomen ten aanzien van het type genitale geslachtsaanpassende operatie.

Omdat er na de genitale GAO bij transmannen een verhoogde kans op urologische complicaties is, is het belangrijk dat de urologie bij de transgenderzorg is betrokken.

Met name na verlenging van de urethra (de wens om staand te kunnen plassen) is er een verhoogde kans (30-40\%) op urethrastricturen en urethrafistels. Deze stricturen komen het meest voor ter hoogte van de anastomose van de pars fixa naar het pars pendulans, waarbij ischemie ter hoogte van de anastomose de meest waarschijnlijke oorzaak is.

De operatieve opties zijn een urethrotomia interna, een urethraplastiek in één tempo (end-end, gesteeld of vrij transplantaat) of in twee tempi (aanleggen van scrotostoma als eerste stadium gevolgd door tubulariseren na minimaal 3 maanden) of aanleggen van een perineostoma als eindoplossing. De recidiefkans op urethrastricturen ligt rond de $40 \%$ [6].

Urethrafistels komen voor in de gehele neo-urethra en ontstaan door dehiscentie van de rij hechtingen of als gevolg van urethrastricturen. Een groot deel van de fistels sluit spontaan. Bij persisteren van de fistel wordt deze minimaal drie maanden na de operatie gesloten. Het optreden van urethrafistels in onze populatie is significant verminderd sinds er standaard voorafgaand aan de genitale GAO met urethraverlenging een colpectomie wordt verricht [7].

Vanwege de grote complicatierisico's bij de vrouw-naarman genitale GAO met plasbuisverlenging wordt in ons centrum ook de GAO zonder plasbuisverlenging aangeboden. In deze groep zien wij een significante afname van het aantal postoperatieve complicaties, een kortere opnameduur, operatieduur en katheterduur.

Zoals hiervoor beschreven worden de testis- en erectieprothese na minimaal zes maanden en 12 maanden geplaatst. Complicaties van de testisprothese komen weinig voor.

Het implanteren van een erectieprothese in de falloplastiek is uitdagend, met name vanwege het ontbreken van een structuur voor het borgen van de cilinders van de prothese. De kans op complicaties en heroperaties na het plaatsen van een erectieprothese is hoog en ligt rond de $40 \%$.

Hoewel het transitie proces zeer ingrijpend is en blijvende consequenties heeft voor de transgenders (bijvoorbeeld ten aanzien van de fertiliteit, medicatiegebruik, mul- 
tipele operaties) zijn deze patiënten bereid om deze offers te brengen, om hun uiteindelijk doel te bereiken: door het leven gaan in het gewenste geslacht.

\section{Conclusie}

De medische zorg voor transgenders is multidisciplinair en complex, waarbij op basis van shared decision making medicamenteuze en chirurgische therapieën worden ingesteld.

De betrokkenheid van de urologen is van belang voor het waarborgen en behoud van mictie en het seksueel functioneren.

Open Access This article is distributed under the terms of the Creative Commons Attribution 4.0 International License (http:// creativecommons.org/licenses/by/4.0/), which permits unrestricted use, distribution, and reproduction in any medium, provided you give appropriate credit to the original author(s) and the source, provide a link to the Creative Commons license, and indicate if changes were made.

\section{Literatuur}

1. APA. DSM-5. Deel II: Genderdysforie. Amsterdam: Boom; 2013.

2. Coleman E, Bockting W, Botzer M, Cohen-Kettenis P, DeCuypere G, Feldman J, et al. Standards of care for the health of transsexual, transgender, and gender nonconforming people. Version 7. Int $\mathbf{J}$ Transgend. 2011;13:165-232.

3. Grift TC van de, Elaut E, Cerwenka SC, Cohen-Kettenis PT, Kreukels BPC. Surgical satisfaction, quality of life, and their association after gender-affirming surgery: a follow-up study. J Sex Marital Ther. 2017;44(2): 138-48.

4. Bouman MB, Sluis WB van der, Buncamper ME, Özer M, Mullender MG, Meijerink WJ. Primary total laparoscopic sigmoid vaginoplasty in transgender women with penoscrotal hypoplasia: a prospective cohort study of surgical outcomes and follow-up of 42 patients. Plast Reconstr Surg. 2016;138(4):614e-23e.

5. Özer M, Pigot GLS, Bouman MB, Grift TC van de, Elfering L, Mello NM van, et al. Development of a decision aid for genital gender-affirming surgery in Transmen. J Sex Med. 2018;15(7):1041-8.

6. Lumen N, Monstrey S, Goessaert AS, Oosterlinck W, Hoebeke P. Urethroplasty for strictures after phallic reconstruction: a singleinstitution experience. Eur Urol. 2011;60(1):150-8.

7. Al-Tamimi M, Pigot GLS, Sluis WB van der, Grift TC van de, Mullender MG, Groenman F, et al. Colpectomy significantly reduces the risk of urethral fistula formation after urethral lengthening in transgender men undergoing genital gender affirming surgery. J Urol. 2018; Aug 30. Epub ahead of print.

drs. Garry Pigot uroloog

drs. Brechje Ronkes uroloog

dr. Mark Bram Bouman plastisch chirurg 